\title{
O CONTO "MADONA DO CAMPO SANTO" DE FIALHO DE ALMEIDA: GÊNESE DE $O$ BARÃO DE BRANQUINHO DA FONSECA?
}

José Maria Rodrigues Filho

Universidade de Mogi das Cruzes

$\mathrm{O}$

s estudos comparados têm como meta auferir dados que resultem em perspectivas notadamente produtivas nas pesquisas de qualquer área do conhecimento literário. A confrontação de textos de autores diversos e de nacionalidades diversas abre perspectivas a múltiplas opções de caminhos analíticos, delineando paralelismos, tangências, descompassos que enriquecem a pesquisa e a análise. Os resultados advindos das propostas comparativistas apresentam contornos ponderáveis, quando são estimadas as posições conjuntivas e disjuntivas dos textos cotejados.

Para se efetivar a comparação, é necessária levar em conta o nível de pertinência dessa comparação. A consonância deve ser flagrante, a fim de não se colocarem em paralelo obras que muito pouco representem de conjuntividade. Aplicando-se esse procedimento, dois autores e obras revelaram concernências, ao serem verificados índices explícitos de intertextualidade, conforme se passará a verificar.

Inicialmente, na história literária estima-se que o período do Realismo em Portugal vai de 1865, iniciando com a Questão Coimbrã, até 1880, com o advento do Simbolismo. Dos autores daquele movimento, um nome se destaca: Fialho D’Almeida. Este ficou conhecido pela sua preocupação com a classe trabalhadora rural na figura dos ceifeiros alentejanos.

Nas obras de Fialho, há duas naturezas que se contradizem: a do artista e a do crítico. Como artista, realizou suas produções com uma profunda acuidade de sentimentos e por uma vibração subjetiva, com a qual pincelava, cromatizando as suas linhas com estro de poeta, embalado pela emoção 
estética. Como crítico, foi um escarnecedor implacável, como se pode observar em Os gatos (publicação mensal de inquérito à vida portuguesa - 18891893), e a julgar já por esta irônica sentença do autor: "Deus fez o homem à sua imagem e semelhança e fez o crítico à semelhança do gato” (D'ALMEIDA, 1945, p.41-43). Como crítico, era irreverente e impiedoso, elaborador de teorias pertinentes e ousadas. A sua obra corresponde ao concurso e ao jogo das impressões e emoções de sua vida e de sua época, ao avaliar os aspectos físicos da Humanidade e da natureza. O rigor de suas observações coloca-o no segmento proselitista dos adjetivos acerca dos pensamentos científicos, revolucionários de sua época: “Este foi, em suma, Fialho D’Almeida, o descritor da cidade e dos ambientes rústicos, o prosador panfletário e o crítico social. Os seus utensílios foram as palavras, a sua linguagem barrocamente organizada..." (MARTINS, 1987, p. 26). O seu temperamento verrinista, afirma J. de Melo Viana em In Memoriam, transitava entre a conversa de bar e a crítica azeda sem reservas (IN MEMORIAM, 1917, p. 78). Fialho ao colaborar em $O$ Atlântico, jornal de grande formato, destinado à América do Sul, escreve, de 1880 a 1884, em folhetins, os primeiros esboços de seus grandes contos.

Com relação ao corpus desta análise comparativa, aqui se inclui o conto Madona do Campo Santo (MCS) que teve o seu primeiro esboço no n. 76 do jornal $O$ Atlântico de 5 de maio de 1882 e foi editado definitivamente, no mesmo ano, na coletânea de contos, $A$ cidade dos vícios (D’ALMEIDA, 1982, p. 166), ainda publicou o conto em edição revista.

É pertinente verificar, no caso da comparação entre $O$ Barão $(\mathrm{OB})$ e o conto Madona do Campo Santo, de Fialho D’Almeida, pela qual se verifica a apropriação de vários temas e motivos por parte de Branquinho da Fonseca, a proposta de Júlia Kristeva (1978, p. 194), para quem a noção de transposição está associada a idéia de intertextualidade. Kristeva considera, também, a possibilidade da passagem de um sistema significante a outro, como fenômeno de ilustração (erudição) no seio das séries literárias. O estatuto da palavra intertextual se caracteriza em introduzir um novo modo de leitura sobre a linearidade do texto.

A referência intertextual explícita do texto de Fialho é ilustrativa, a esse respeito, ao ser enfatizado o episódio da procura de uma rosa branca por parte do Barão e do Inspetor, no passo em que há a indagação do Inspetor ao Barão: "São 
para a Madona do Campo Santo" (FONSECA, 1972, p. 82), em que a alusão, em menção explícita do conto Madona do Campo Santo, acaba fazendo parte integrante da sintagmática do texto de $O$ Barão, como um eco advindo do étimo-texto ou texto-origem. Esse procedimento acarreta uma espécie de anamnese intelectual, em que a referência intertextual é tida como um elemento paradigmático resgatado (deslocado) e originário de uma outra sintagmática, com relação às características da estética cientificista e decadentista do final do século XIX, época da elaboração do conto por Fialho D’Almeida.

No entanto, a pertinência dessa comparação reside no ato da confrontação entre o original datilografado localizado pelo autor deste artigo no Museu dos Castros e Guimarães - Cascais - Portugal. Para o Centro de Estudos Portugueses da Universidade de São Paulo, foi doada uma fotocópia do referido original.

Conforme se pode comparar com as fotocópias do original datilografado, e das primeira e segunda edições, na fala do Inspetor, a pergunta se dá

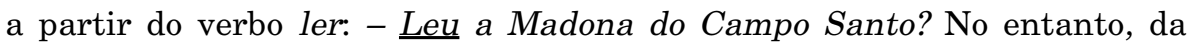
terceira edição em diante a inquirição é feita de uma maneira não indicativa do título do conto: $\underline{\text { São }}$ para a Madona do Campo Santo? Houve uma mudança do verbo $\underline{\text { ler }}$ para o verbo $\underline{\text { ser }}$ por parte do autor. Daí a razão de a Fortuna Crítica de $O$ Barão não se preocupar com esse nome que sempre apareceu no texto, marcado com aspas. Talvez ficasse para o crítico e para o leitor a indicação referente ao nome de alguma santa que o Inspetor na sua ingenuidade pensou que fosse algo dileto do Barão, seu hospedeiro e que as flores seriam para ela.

Para melhor esclarecer este fato de intertextualidade explícita, devemse observar as fotocópias em ordem cronológica. Com relação ao aparecimento do termo Madona do Campo Santo, no texto de $O$ Barão, fica pressuposto que as condições de legibilidade literária apontam para a questão da fusão ou um efeito de eco pela interferência da intertextualidade implícita ou explícita, maior ou menor referência ao étimo-texto. Além das fronteiras da intertextualidade, a obra literária depara com condições de incompreensibilidade, quando é registrado o aparecimento de uma palavra desconhecida, enquanto não se descobre a sua procedência. No caso de $O$ Barão, o termo "Madona do Campo Santo" sempre foi escrito em itálico e com aspas. Sendo assim, na vida de leituras feitas da novela um conceito se interpõe: Só se 
apreende a estrutura do sentido e a estrutura dessa obra se ela for relacionada com os seus arquétipos, abstraídos de longas séries de textos. Esses arquétipos, provenientes de outras fontes ou gestos literários, codificam as formas e os usos da tradição literária. É em relação aos modelos arquétipos que a obra "entra sempre numa relação de realização, transformação ou de transgressão” (JENNY, 1979, p.5). É essa relação que a define e, quando concebida fora de um sistema, a obra é, pois, impensável. Talvez, seja essa a razão dessa alusão ao conto de Fialho, na fala do Inspetor.

Para a compreensão dessa instância discursiva, pressupõe-se uma pesquisa em séries diversas para a decodificação de termos usados na linguagem literária, e, pela pesquisa, adquire-se o reconhecimento de uma multiplicidade de textos envolvidos. A crítica formal, nesse caso, revela os fundamentos da intertextualidade que, hoje, se situam relativamente ao funcionamento da literatura. O conceito básico, sob o ângulo intertextual, remete-se implícita ou explicitamente a textos outros, com apoio da teoria da crítica genética com a qual a obra tem conluio intertextual, pelo enfoque da crítica das fontes. No caso pelo confronto com o original datilografado (localizado ou descoberto em boa hora), pode-se observar tal evidência.

Os condicionantes a esse enquadramento intertextual explicam o uso do código e o nível do conteúdo formal da obra. Isso acontece com todos os textos que deixam transparecer a sua relação com outros textos: imitação, paródia, citação, montagem, plágio etc.

O grau de explicitação da referência intertextual ao conto de Fialho D’Almeida, a partir do uso da onosmática em Madona do Campo Santo, no discurso de $O$ Barão, fica mais detalhado no episódio da busca de uma rosa branca pelo Barão em seu hortus e ultrapassa não só os graus de caracterização do plano novelesco do conto como também se viabiliza em marcadores enuncivos do discurso. O enunciado está emblematicamente marcado com aspas e inserido na estrutura conversacional do diálogo entre o Barão e o Inspetor no episódio da procura da rosa, motivo símbolo, como uma citação literal. Para elucidar melhor tal enfoque, na tentativa de fundamentar essa observação, a lição de Laurent Jenny vem a calhar: "É claro que, em toda uma categoria de casos, para provar um fato intertextual podem servir critérios estruturais; mas já se torna mais difícil determinar se o fato intertextual deriva do código ou é a própria matéria da obra” (JENNY, 1979, p. 19). 
Daí, a razão de nunca haver sido relacionada a intercorrência do conto de Fialho D’Almeida, na novela de Branquinho da Fonseca. Foi graças ao cotejo com o original datilografado e com a primeira edição de $O$ Barão, que foi possível apontar o étimo do termo em foco. Muito ajudou a comparação com a adaptação teatral elaborada pelo dramaturgo Luís de Sttau Monteiro, que será vista mais adiante.

A compatibilidade da pertinência desse cotejo reside nas posições do fato intertextual, já que as duas obras manifestam fortes traços de semelhanças. Vale dizer que a sondagem implica na averiguação, a partir das confrontações dos dados originais de $O$ Barão com as edições seguintes que possibilitaram a percepção dessa apropriação (repetição). Como são obras de épocas muito distintas e distantes, ou seja, do período do Realismo, séc. XIX e do Segundo Modernismo, séc. XX, tal consonância existe evidentemente em função da cultura e da memória de cada época e demonstra as preocupações formais e ideológicas dos escritores envolvidos. É por essa razão que os modos de leitura de cada época correspondem à competência dos leitores em poder relacionar suas inferências com os outros textos. No caso, a passagem do gênero conto para o gênero novela também se apresenta como um fato a ser avaliado.

No discurso de Fialho, em que o espaço citadino é o grande pano de fundo para as degenerescências humanas, "influências das leituras de Lombroso, o conto Madona do Campo Santo é caracterizado como uma narrativa marcada por sugestões de Realismo agonizante e das últimas e anacrônicas manifestações do Romantismo, encobertas em Decadentismo" (PIMPÃO, 1945).

O enredo do conto de Fialho, agora, numa síntese a fim de se ponderar em certos aspectos temáticos e motívicos, trata da história de Artur, um escultor fracassado que se enamora de Judite, irmã de seu melhor amigo. Judite nos seus dezesseis anos vive angelicamente dentro de casa, seus contatos com o mundo exterior praticamente se resumem na permanência à janela enquanto observa Artur em seus afazeres diários. Certo dia, Artur descobre que Judite era portadora de uma terrível patologia: a de se alimentar somente de rosas brancas. Depois de certo tempo, Judite adoece e 
vem a falecer, não obstante os intensos cuidados de Artur e de seus familiares. Artur, profundamente abalado, se isola na tentativa de esculpir uma estátua que receberia o nome de Madona do Campo Santo cujo esboço, num momento de desesperadora saudade da amada morta, destrói a marteladas.

A ambiência patológica se adensa em torno da personagem central Judite que é a tradução da degenerescência psíquica ou de quem sucumbe em meio a pustulências descritas em planos líricos decadentes (MOISÉS, 1981, p. 246) , diferente da história centrada na Judite bíblica. A ambivalência do tom patológico e do lírico perpassa o conto Madona do Campo Santo, tonificando-o num estilo de riquezas plásticas, oriundas de alucinações cromáticas a pulverizarem a efabulação, e assim é construída a intriga, bem como o desfecho com soluções raras e exóticas.

Pouco se sabe acerca deste conto de Fialho D'Almeida. Nem todos os críticos da época deram atenção ao conto Madona do Campo Santo. Afonso Vargas destaca, em suas observações, as qualidades desse conto, visto como uma pérola de mais ideal transparência. $\mathrm{E}$ o emérito estudioso da obra de Fialho, Álvaro Pimpão, considera Madona do Campo Santo uma grande refundição do conto $A$ máscara de gesso publicado no jornal $O$ Atlântico n.․․ 76 de 28 de abril de 1882, editado dias antes de publicar a Madona. Na edição comemorativa In Memoriam, Antonio Correa publica um soneto intitulado Madona do Campo Santo (PIMPÃO, 1945, p. 190).

Os críticos e leitores que não tiveram acesso à primeira edição de $O$ Barão, pela Editorial Inquérito, nunca puderam encontrar a parte indicativa do étimo da novela que ora foi posto em questão, a respeito do verbo ler revelador. No entanto, o dramaturgo Luís de Sttau Monteiro, ao utilizar a primeira edição de $O$ Barão em sua adaptação teatral, se acercou deste verbo, mantendo-o no texto da peça.

Pelo processo de transdutibilidade dos gêneros narrativo, poético e dramático, são empreendidas adaptações para teatro de obras literárias. Romances, novelas e contos têm sido transmutados para o domínio dos textos dramáticos, cinematográficos, televisivos e videográficos. Esse procedimento encontra, na teoria das relações intersemióticas, o instrumento mais adequado e preciso para pontuar essa passagem. Nesse campo, a novela $O$ Barão foi adaptada para o teatro pelo dramaturgo português Luís de Sttau Monteiro (1974) em 1965, o qual utilizou para a sua adaptação a primeira 
edição da novela. E é ai que começam a ocorrer as pertinências analógicas em relação ao verbo ler na frase: “Leu a Madona do Campo Santo?” Estes fatos fizeram com que esta pesquisa empreendesse a procura dos originais e da primeira edição.

Por meio da adaptação para as artes visuais, os episódios da novela vão tomando o vigor da mimesis cinésica, recriando a vitalidade do discurso literário, fazendo com que as personagens se projetem além do texto escrito, realizando-se nas possibilidades da manifestação do espetáculo do palco.

No caso, a personagem do Barão, no palco, acabou se aproximando da figura do ditador Antonio de Oliveira Salazar. Por essa razão, a adaptação de $O$ Barão de Luís de Sttau Monteiro não chegou a ser apresentada ao público, pois foi proibida pela Censura/PIDE na sua pré-estréia, no Teatro Vasco Morgado em Lisboa, em 1965 (BARATA, 1991, p. 352/379). O que restou foi somente a publicação pela Ática, do guião da peça, que pouca divulgação recebeu.

No episódio em que o Barão e o Inspetor estão no jardim do solar, colhendo flores para levarem à Madona do Campo Santo, este termo sempre foi emblematicamente pontuado com aspas, e na adaptação de Sttau Monteiro foi conservado conforme o original datilografado e a 1. edição.

$\mathrm{O}$ fato de o Inspetor indagar se as violetas (rosas) eram para a Madona do Campo Santo, remete-se a situações episódicas comumente relacionadas a uma oferenda feita a alguma Santa, por essa razão, essa passagem da narrativa sempre foi desconsiderada dessa maneira pelos leitores e pela crítica. No entanto, quando foram pontuados os aspectos conjuntivos e disjuntivos no cotejo entre o texto de Branquinho da Fonseca e a adaptação teatral de Sttau Monteiro, verbos de ação, tais como o verbo comer e o verbo ler interpuseram-se como mais um agente revelador de intertextualidade explícita com relação ao étimo-texto de Fialho D’Almeida.

Segue-se o trecho da adaptação de Sttau Monteiro, o qual utilizou o processo de translocução, permanecendo quase que a totalidade do diálogo, encontrado no étimo branquiniano, determinado dramaticamente pelas rubricas de ação, locação e intenção. 
(Rubrica) - ... Passado um instante, ajoelha-se e representa mimicamente, a ação de apanhar flores. O Inspetor, muito ébrio, debruçase para observar o amigo.

Inspetor - Violetas... São para comer?

(Rubrica) - O Barão não responde e, passado um instante, o Inspetor insiste.

Inspetor - Leu a "Madona do Campo Santo"? O Barão permanece em silêncio mas, de repente, levanta-se e exclama.

Barão - Tens razão. Violetas é piegas... Uma rosa... Uma rosa é que está certo.

Inspetor - Para quem?

Barão - Para ela. (MONTEIRO, op. cit, p. 103).

No confronto com o original datilografado e com as primeira e segunda edições de $O$ Barão, pode-se somente, detectar a presença do verbo ler, “Leu a Madona do Campo Santo?”, profundamente tematizado com o conto fialhiano, este como obra para ser lida.

Neste caso, da adaptação de Sttau Monteiro, pelo processo de comparação, como se pode observar, houve mais um verbo revelador, além do verbo ler, foi o verbo comer, na adaptação teatral de 1965. A partir desse índice, acrescido da insinuação que o Inspetor faz sobre a possibilidade de comer as violetas, foi possível chegar seguramente até o texto de Fialho em que a jovem Judite patologicamente desenvolve uma febril necessidade de se alimentar de rosas brancas.

Seguindo esse caminho, ao ser efetuada a análise comparativa, outros elementos temáticos e motívicos surgiram alcançados pela investigação. Assim, tem-se a certeza de que Sttau Monteiro conhecia esta referência intertextual explícita, a partir da utilização em sua adaptação da primeira edição de $O$ Barão. Na seqüência dos fatos, a peça foi proibida e a publicação pela Ática não atingiu o público interessado, fazendo com que o dramaturgo abandonasse a empreitada adaptativa e o espetáculo.

Com o auxílio dos pressupostos da crítica genética, os estudos comparativos voltam-se para os estudos de fontes. A exegese do texto de Fialho D’Almeida, Madona do Campo Santo demonstra, pela comparação com a narrativa de $O$ Barão, a evidência do processo de coalescência ou de apropri- 
ação e/ou de junção das partes, em função de motivos e de temas que foram aclimatados ao enredo, e que, também, são localizáveis em textos outros.

Uma forma de endogênese e exogênese por recorrência é o que se pode ponderar. Pierre-Marc de Biasi (1997, p. 34-35) considera essas apropriações esclarecedoras, na medida em que a exogênese representa a seleção e apropriação das fontes tópicas tradicionais e a endogênese, a produção e transformação dos estudos redacionais, itens observados na genética de roteiros ou de pré-textos, que se apresentam, na forma de conceitos básicos para a história genética da cultura literária.

Com esses preceitos emprestados da crítica genética, aclaram-se os parâmetros obscuros do mito da criação os quais possibilitarão o acolhimento cognitivo mais preciso do obscuro campo autoral. Esse processo possibilita o conhecimento exato da operação cognitiva dos autores em relação a outros autores, pelas recorrências e formulações lingüístico-poéticas que presidiram, no caso, o ato da construção do discurso branquiniano. $\mathrm{O}$ remetimento ao texto de Fialho D’Almeida, conduzido pela declaração explícita ao conto Madona do Campo Santo, promove a formulação da hipótese de situar a sociogênese da intertextualidade, por meio do inventario de leituras do autor de $O$ Barão, como princípio construtivo, a partir da localização de uma outra textualidade referencial.

Na seqüência desta análise, outro aspecto recorrente se apresenta com igual importância. O motivo rosa aparece em ambos os textos, representando o tema da figura da mulher e do amor, bem como dotado da conotação de pureza, perfeição e plenitude. A patogenia e a conseqüente morte de Judite comparam-se, de certa forma, ao tema da morte de Ofélia em Hamlet, recuperado da tradição retórica, no episódio de sua morte, no qual ela é velada envolta em flores, predominantemente rosas brancas. O motivo rosa, também aparece no conto $A$ Princesinha das Rosas (D’ALMEIDA, 1982, p. 135) de Fialho D'Almeida, como outra fonte de recorrência, que demonstra o princípio da eleição temático-motívica do autor de elementos de valor simbólico consagrados pela tradição retórica. Jacinto Prado Coelho considera Fialho D’Almeida, em alguns textos e a despeito de sua veia de crítico mordaz, o Poeta das rosas (COELHO, 1944, p. 16).

No que diz respeito à novela branquiniana em $O$ Barão há um gesto simbólico executado pelo Barão, o de erguer a mão empunhando uma rosa 
branca, que faz o Inspetor exprimir, em tom de digressão, estas palavras: "Lembrei-me daquela rosa branca, erguida na mão como um símbolo de pureza e vi a beleza de tal gesto, cujo destino eu ignorava, mas para o qual ele me tinha pedido auxílio" (p. 100). As considerações do Inspetor a respeito do signo gestual, considerando-o um símbolo de pureza e de beleza, acabam confirmando a semântica e a simbologia do motivo recorrente rosa, encontradas nos compêndios de simbologia universal.

Trata-se, aqui, de aplicação da arqueologia textual, atividade própria da pragmática de localização dos ecos e vozes intertextuais, admitindo-se, então, as duas espécies de genéticas literárias, no campo da intertextualidade: a genética roteirística, ou pré-textual, e a genética do manuscrito que se mostrou pertinente ou adequada neste artigo, pela descoberta dos originais datilografados da novela $O$ Barão, nos quais a confirmação da proveniência do intertexto se apresenta claramente. Ficam, assim, ressaltadas nesse campo as relações genéticas "que unem numa sintonia imediatamente anterior ao nascimento da obra, a série de fatos históricos, a série dos discursos e a produção do texto" (MITERRAND, 1989, p. 143), detectadas no âmbito da comparatividade.

\section{BIBLIOGRAFIA}

BARATA, José de Oliveira. História do teatro português. Lisboa: Universidade Aberta, 1991. BIASI, Pierre-Marc. “A crítica genética”. In: BERGEZ, Daniel et alii. Métodos críticos para a análise literária. São Paulo: Martins Fontes, 1997.

COELHO, Jacinto do Prado. As melhores páginas da literatura português - Fialho de Almeida. Lisboa: Sociedade Editorial e Livraria - Livraria Rodrigues, 1944.

D’ALMEIDA, Fialho. “A Princesinha das Rosas”. In: O país das uvas. 12.ed. Lisboa: Clássica Editora, 1982.

—. Os Gatos. Lisboa: Clássica, 1945, vol. I

—. Cidade dos vícios.10.ed. Lisboa: Livraria Clássica Editora, 1982.

FONSECA, Branquinho da. O Barão. Lisboa: Portugália, 1972.

IN MEMORIAM. Fialho D’Almeida. Organizado por Antonio Barradas e Alberto Saavedra - no sexto aniversário da morte do escritor. Porto, Tipografia Renascença Portuguesa, 1917. JENNY, Laurent. “A Estratégia da Forma”. In: Intertextualidades - Poetique, n.ำ27, Coimbra, Almedina, 1979. 
KRISTEVA, Júlia. Recherches pour une Sémanalyse. Paris: Seuil, 1978.

MARTINS, Maria da Graça Orge. "Introdução”, in: Fialho D’Almeida. O pais das uvas. Póvoa de Varzim: Editora Ulisséia, 1987.

MITERRAND, Henri. “Critique Génétique et Histoire Culturelle”. In: HAY, Louis e CORTI, José. Renaissence du Texte, 1989.

MOISÉS, Massaud. A literatura portuguesa. 17.ed. São Paulo: Cultrix, 1981.

MONTEIRO, Luís de Sttau. O Barão. 2.ed. Lisboa: Ática, 1974.

PIMPÃO, Álvaro J. da Costa. Fialho I. Introdução ao Estudo de sua Estética. Coimbra: Coimbra Editores, 1945. 